\title{
Produção e Qualidade de Forragem da Mistura de Gramíneas Anuais de Estação Fria sob Pastejo Contínuo
}

\author{
Cledson Roso ${ }^{1}$, João Restle ${ }^{2}$, André Brugnara Soares ${ }^{1}$, Dari Celestino Alves Filho ${ }^{3}$, Ivan Luiz Brondani ${ }^{3}$
}

\begin{abstract}
RESUMO - A produção e a qualidade de forragem da pastagem composta por misturas de gramíneas anuais de estaçao fria sob pastejo contínuo foram avaliadas. As misturas usadas foram: T1 - Triticale (X Triticosecale) + azevém (Lolium multiflorum); T2 - Aveia preta (Avena strigosa) + azevém; e T3 - Triticale + aveia preta + azevém. A semeadura, a lanço, foi realizada no dia 21/04/95, sendo a área adubada com $200 \mathrm{~kg} / \mathrm{ha}$ (05-30-15). A adubação de cobertura foi de $175 \mathrm{~kg} / \mathrm{ha}$ de nitrogênio, na forma de uréia e parcelada em quatro aplicações. O estabelecimento da pastagem ocorreu de 21/04 a 08/06/95 e o pastejo estendeu-se até 14/11/95. Os componentes triticale e aveia preta apresentaram maior participação nas avaliações iniciais do resíduo e o azevém nas avaliações finais. A taxa de acumulação foi 50,8; 55,6; e 42,1 kg de MS/ha•dia; o teor de proteína bruta (PB), 17,7; 18,1; e 16,2\%; a digestibilidade in vitro da matéria orgânica (DIVMO), 56,4; 56,7; e 57,5\%; a porcentagem de MS no resíduo, 23,0; 21,2; e 23,2\%; e a produção total de matéria seca, 9696,10273 e $8041 \mathrm{~kg}$ de MS/ha, respectivamente, para T1, T2 e T3. A mistura de triticale mais azevém apresentou melhor distribuição na produção e maior estabilidade na qualidade de forragem durante o período de pastejo.
\end{abstract}

Palavras-chave: aveia preta, azevém, composição botânica, dinâmica, pastejo, produtividade, qualidade, triticale

\section{Production and Quality of Forage of Annual Temperate Grasses Mixtures under Continuous Grazing Condition}

\begin{abstract}
The production and quality of forage of annual temperate grasses mixtures under continuous grazing condition were evaluated. The mixtures used were: T1 - Triticale (X Triticosecale) plus ryegrass, T2 - Oat (Avena strigosa) plus ryegrass, and T3 - Triticale plus oat plus ryegrass. Broadrast sowing occurred at 04/21/95, being the area fertilized with 200 kg/ha (05-30-15). The broadcast fertilization was of $175 \mathrm{~kg} / \mathrm{ha}$ of nitrogen in urea form and it was subdivided in four applications. The establishment of the pasture occurred from $04 / 21$ to $06 / 08 / 95$ and grazing period was extended in to $11 / 14 / 95$. The component triticale and oat presented higher contribution in the initial evaluation of the botanical composition of the residue and the ryegrass in the final evaluations. The accumulation rate was $50.8,55.6$, and $42.1 \mathrm{~kg} \mathrm{DM} /$ ha $\bullet$ day; crude protein content, 17.7, 18.1, and $16.2 \%$, in vitro organic matter disappearance, 56.4,56.7, and 57.5\%, the \% DM of the residue, 23.0,21.2, and 23.2; and total forage production, 9,696, 10,273, and 8,041 kg DM/ha for T1, T2 and T3, respectively. The mixture of triticale plus ryegrass showed better distribution of production and higher stability in quality during the grazing period.
\end{abstract}

Key Words: black oat, ryegrass, botanical composition, dynamic, grazing, productivity, quality, triticale

\section{Introdução}

Com a intensificação e a necessidade de maior competitividade na produção de bovinos de corte, a necessidade por tecnologia aumenta e seu correto entendimento e aplicação assumem papel fundamental para a sobrevivência dos sistemas de produção. A estacionalidade de produção e a baixa qualidade das pastagens nativas do Rio Grande do Sul tornam a pecuária de corte ineficiente e sem competitividade nos sistemas de produção em que a base da alimentação é o campo nativo. A utilização de gramíneas anuais de estação fria como pastagens é excelente alternativa de produção de forragem em sistemas de rotação com as culturas de verão, visando suprir a deficiência alimentar ocasionada por baixas temperaturas, geadas e pouca luminosidade do outono - inverno, que reflete a baixa produção e qualidade do campo nativo.

As misturas de espécies forrageiras anuais de inverno visam combinar os picos de produção de matéria seca que são atingidos em diferentes épocas, de acordo com a espécie, resultando no aumento da produção e do período de utilização da pastagem. Resultados de pesquisa com aveia preta mais azevém sob pastejo, avaliando a produção e qualidade de forragem e produção animal (LUPATINI et al.,

\footnotetext{
1 Eng. Agr ${ }^{\circ}$, Mestrando em Zootecnia, UFSM, Departamento de Zootecnia da UFSM, CEP 97119900 - Santa Maria - RS.

2 Eng. Agr ${ }^{\circ}$, Ph.D., Professor Titular, Bolsista do CNPq, Departamento de Zootecnia da UFSM.

3 Professor Assistente, Departamento de Zootecnia da UFSM.
} 
1998; RESTLE et al., 1998), demonstram o grande potencial de produção de forragem destas espécies quando associadas.

Outras espécies de gramíneas de estação fria são alternativas que podem ser utilizadas em misturas com o azevém no inverno. Entre elas, o triticale tem demonstrado resultados promissores na produção de grãos e forragem, destacando-se por sua rusticidade e produtividade, conforme resultados encontrados por BAIER (1989), apresentando grande potencial de adaptabilidade para as condições brasileiras (BAIER e NEDEL, 1985). No entanto, são inexistentes informações sobre a dinâmica e produção de forragem do triticale em misturas com gramíneas anuais de estação fria nas condições de pastejo, no Rio Grande do Sul.

O objetivo deste trabalho foi avaliar a dinâmica, a produtividade e a qualidade das pastagens compostas pela mistura de gramíneas anuais de estação fria na condição de pastejo, para que as informações geradas possam servir de base na escolha das espécies para formar uma mistura forrageira que mais se adapte aos sistemas de produção, visando torná-los mais eficientes, competitivos e lucrativos.

\section{Material e Métodos}

O experimento foi conduzido sobre solo Podzólico Vermelho - Amarelo, no Departamento de Zootecnia da Universidade Federal de Santa Maria, situada na Depressão Central do Rio Grande do Sul, numa altitude de $95 \mathrm{~m}$, latitude $29^{\circ} 43^{\prime}$ ' sul e longitude $53^{\circ} 42^{\prime}$ oeste. O clima da região é o cfa (subtropical úmido), conforme a classificação Köppen (MORENO, 1961).

Foram estudadas e comparadas as seguintes misturas: T1 - Triticale (X Triticosecale) e azevém (Lolium multiflorum), T2 - Aveia preta (Avena strigosa) e azevém, T3 - Triticale, aveia preta e azevém.

A área experimental constou de nove piquetes de 1 ha cada um, sendo que cada piquete representava uma unidade experimental. A área do presente experimento vem sendo utilizada há vários anos com pastagens de gramíneas de ciclo anual, em experimentos com produção animal, recebendo adubações de base conforme as RECOMENDAÇÕES DE ADUBAÇÃO E CALAGEM PARA OS ESTADOS DO RIO GRANDE DO SUL E SANTA CATARINA (1989).

O preparo do solo constou de gradagem pesada com grade aradora e gradagem leve com grade niveladora. Na adubação de manutenção, realizada a lanço após a gradagem pesada, foram utilizados $10 \mathrm{~kg}$ de $\mathrm{N}, 60 \mathrm{~kg}$ de $\mathrm{P}_{2} \mathrm{O}_{5}$ e $30 \mathrm{~kg}$ de $\mathrm{K}_{2} \mathrm{O}$ por ha. A semeadura, a lanço, foi realizada em 21 de abril de 1995, utilizando as seguintes quantidades de sementes: $\mathrm{T} 1$ - $150 \mathrm{~kg} / \mathrm{ha}$ de triticale mais $30 \mathrm{~kg} / \mathrm{ha}$ de azevém, T2 - $65 \mathrm{~kg} / \mathrm{ha}$ de aveia preta mais $30 \mathrm{~kg} / \mathrm{ha}$ de azevém, T3 - $75 \mathrm{~kg} / \mathrm{ha}$ de triticale mais $33 \mathrm{~kg} / \mathrm{ha}$ de aveia preta mais $30 \mathrm{~kg} / \mathrm{ha}$ de azevém, sendo as sementes incorporadas com grade de dentes. Na adubação nitrogenada foram aplicados $175 \mathrm{~kg} / \mathrm{ha}$ de nitrogênio em cobertura, na forma de uréia, parceladas em quatro aplicações, a primeira no perfilhamento $(18 / 05)$ e as demais durante a utilização da pastagem (26/07, 19/08 e 21/09 de 1995).

O início da utilização da pastagem ocorreu no dia 08/06/95, por meio de pastejo contínuo com terneiras de idade média de 7 meses e peso médio inicial de 148 $\mathrm{kg}$, utilizando oferta de forragem pretendida de $10 \%$ de peso vivo (PV), ou seja, $10 \mathrm{~kg}$ de MS disponível para cada $100 \mathrm{~kg}$ de $\mathrm{PV} /$ dia.

Os resíduos da pastagem foram avaliados a cada 35 dias aproximadamente, cortando-se rente ao solo dez amostras $\left(0,25 \mathrm{~m}^{2}\right)$ em cada piquete. A forragem proveniente destas amostras foi homogeneizada, sendo retiradas duas amostras compostas. Uma amostra foi pesada e levada para estufa a $65^{\circ} \mathrm{C}$ por no mínimo 72 horas para determinação do teor de matéria seca (MS) e posteriormente preparada para determinação da qualidade do resíduo. A outra amostra foi utilizada para a avaliação da composição botânica da pastagem, sendo separadas as espécies que compunham as misturas, inço e material morto. Após a separação botânica os componentes foram colocados em estufa a $65^{\circ} \mathrm{C}$ para determinar o percentual em base na MS. Estas amostras, após a secagem, foram moídas em moinho tipo Wiley, com peneira de malha de $1 \mathrm{~mm}$ e guardadas em sacos plásticos para posterior análises bromatológicas, em que se determinaram o teor de nitrogênio pelo método micro kjeldahl (AOAC, 1984) e digestibilidade in vitro da matéria orgânica (TILLEY e TERRY, 1963). O teor de proteína bruta (PB) foi obtido multiplicando o teor de $\mathrm{N}$ pelo fator 6,25 .

A taxa de acumulação de matéria seca foi avaliada em datas próximas às das avaliações dos resíduos, usando três gaiolas de exclusão ao pastejo por piquete, seguindo a técnica do triplo emparelhamento. A produção total de MS foi obtida pelo somatório das produções dos períodos (taxa de acumulação $\mathrm{x} \mathrm{n}^{\mathrm{O}}$ de dias) mais o resíduo inicial.

O delineamento experimental foi o inteiramente casualizado, com três repetições (piquetes). Os dados foram submetidos à analise de variância (SAS, 
1990), por intermédio do GLM e teste da probabilidade da diferença (pdiff) a 5\% de significância, sendo usado o seguinte modelo matemático:

em que

$$
\mathrm{Y}_{\mathrm{ikj}}=\mu+\mathrm{T}_{\mathrm{i}}+\mathrm{P}_{\mathrm{k}}+\mathrm{TP}_{\mathrm{ik}}+\mathrm{E}_{\mathrm{ij}}
$$

$\mathrm{Y}_{\mathrm{ikj}}=$ variáveis dependentes;

$\mu$ média de todas as observações;

$\mathrm{T}_{\mathrm{i}} \quad=$ efeito do tratamento de índice $\mathrm{i}$;

$\mathrm{P}_{\mathrm{k}}=$ efeito do período de índice $\mathrm{k}$;

$\mathrm{TP}_{\mathrm{ik}}=$ interação entre tratamento de índice i e período de índice $\mathrm{k}$; e

$E_{i j}=$ erro aleatório associado a cada observação $\mathrm{j}$.

\section{Resultados e Discussão}

Os dados de precipitação e temperatura média do período experimental são apresentados na Tabela 1, na qual se observa que as precipitações foram inferiores às normais, principalmente no estabelecimento e no final do período de utilização das pastagens, sendo que no total do período experimental ocorreu déficit de $285 \mathrm{~mm}$ em relação às precipitações normais. As temperaturas médias foram normais na maioria dos meses de utilização das pastagens.

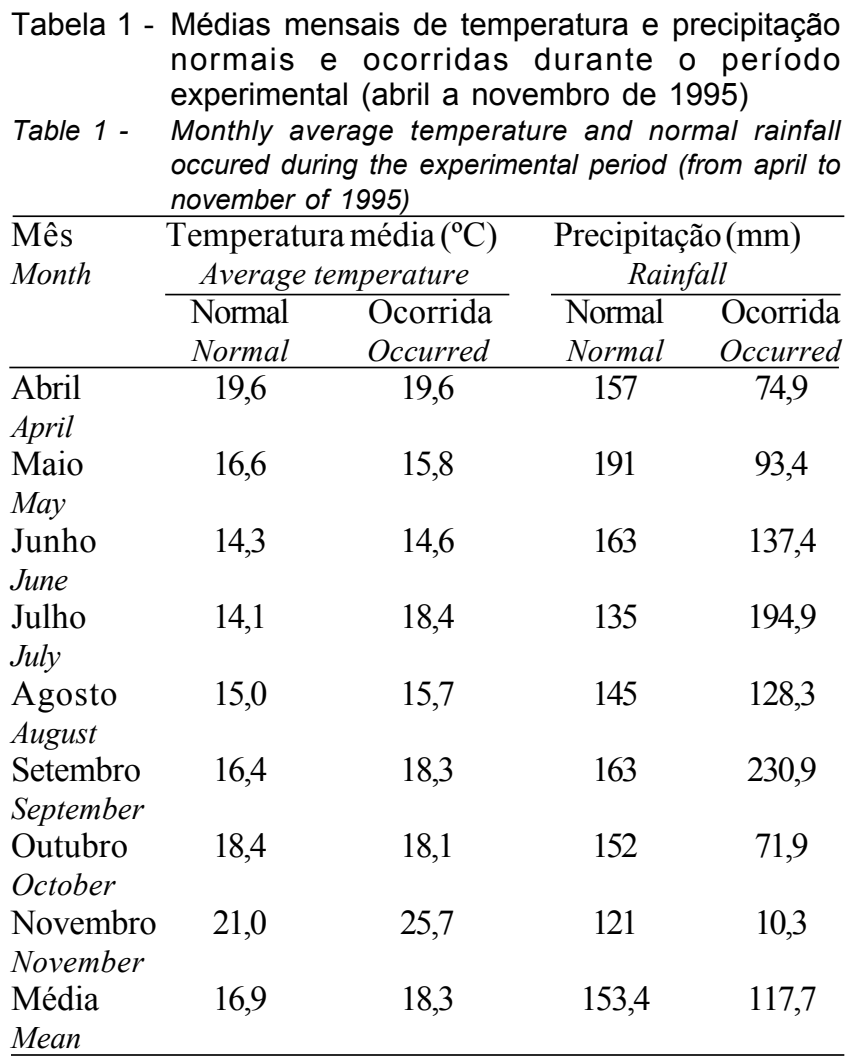

Na Tabela 2 encontra-se o resumo da análise de variância para as variáveis estudadas na pastagem. A análise de variância mostrou que houve interação significativa entre tratamento e período somente para a variável teor de proteína bruta do resíduo. Portanto, os resultados das demais variáveis serão discutidos em função dos efeitos principais, tratamento e período.

Os resíduos de matéria seca foram semelhantes entre as misturas; na média do período experimental foram de $1670 \mathrm{~kg}$ de $\mathrm{MS} / \mathrm{ha}$, pois, após as avaliações do resíduo, foi feito o ajuste da carga animal, procurando-se manter a mesma oferta de forragem ( $10 \%$ do peso vivo).

Conforme pode ser verificado na Tabela 3 , a taxa de acumulação média diária de matéria seca foi influenciada pela mistura. A taxa de acumulação de matéria seca foi semelhante nas misturas de azevém com triticale ou aveia preta, mostrando valores superiores à obtida na mistura de azevém com triticale e aveia preta, sendo respectivamente 50,$8 ; 55,6$; e 42, 1 $\mathrm{kg}$ de $\mathrm{MS} / \mathrm{ha} /$ dia. A menor taxa de acumulação média diária de matéria seca na mistura que inclui triticale e aveia preta foi causada pela concorrência destas espécies, que apresentam hábitos fenológicos similares (Tabela 4), resultando inclusive na redução da taxa de acumulação do azevém.

Os resultados encontrados para taxa de acumulação média diária de matéria seca são inferiores aos encontrados por RESTLE et al. (1998), LUPATINI et al. (1998) e LESAMA (1997) na mistura de aveia

Tabela 2 - Resumo da análise de variância para digestibilidade in vitro da matéria orgânica (DIVMO), teor de proteína bruta (PB), taxa de acumulação e porcentagem de matéria seca no resíduo

Table 2 - Summary of analysis of variance for in vitro organic matter disappearance (IVOMD), crude protein (CP), accumulation rate and percentage dry matter of the residue

\begin{tabular}{|c|c|c|c|c|}
\hline & $\begin{array}{l}\text { DIVMO } \\
I V O M D\end{array}$ & $\begin{array}{l}\text { PB } \\
C P\end{array}$ & $\begin{array}{l}\text { Tx. Acum. } \\
\text { Accum.rate }\end{array}$ & $\begin{array}{l}\mathrm{MS} \\
D M\end{array}$ \\
\hline & & & & \\
\hline $\begin{array}{l}\text { Tratamento }(\mathrm{T}) \\
\text { Treatment }\end{array}$ & 5,80 & $17,30^{*}$ & $849,22 * *$ & $20,59 *$ \\
\hline $\begin{array}{l}\text { Período }(\mathrm{P}) \\
\text { Period }\end{array}$ & $437,88 * *$ & $387,88 * *$ & $397,00 * *$ & $1381,66^{* *}$ \\
\hline $\mathrm{T}^{* \mathrm{P}}$ & 26,49 & $4,81^{*}$ & 31,93 & 5,49 \\
\hline Resíduo & 13,95 & 2,04 & 58,89 & 4,20 \\
\hline $\begin{array}{l}\text { Residue } \\
\text { gl do resíduo } \\
\text { df of residue }\end{array}$ & 36 & 36 & 36 & 36 \\
\hline CV\% & 6,56 & 8,35 & 15,50 & 9,12 \\
\hline
\end{tabular}


Tabela 3 - Taxa de acumulação média diária (kg de MS/ha) em cada mês e média da pastagem com misturas de gramíneas anuais de estação fria sob pastejo contínuo

Table 3 - Daily average dry matter accumulation ( $\mathrm{kg}$ of $\mathrm{DM} / \mathrm{ha}$ ) rate in each month and average of the pasture of annual temperate grasses mixtures under continuous grazing

\begin{tabular}{|c|c|c|c|c|c|c|c|}
\hline \multirow[t]{3}{*}{$\begin{array}{l}\text { Tratamento } \\
\text { Treatment }\end{array}$} & \multicolumn{7}{|c|}{$\begin{array}{l}\text { Mês } \\
\text { Month }\end{array}$} \\
\hline & 08/06a30/06 & 01/07a31/07 & 01/08a31/08 & 01/09a 30/09 & 01/10а $31 / 10$ & $01 / 11$ a $14 / 11$ & Média \\
\hline & $06 / 08$ to $06 / 30$ & $07 / 01$ to $07 / 31$ & $08 / 01$ to $08 / 31$ & $09 / 01$ to $09 / 30$ & $10 / 01$ to $10 / 31$ & $11 / 01$ to $11 / 14$ & Mean \\
\hline $\begin{array}{l}\text { Triticale+Azevém } \\
\text { Triticale+Ryegrass }\end{array}$ & 59,6 & 53,8 & 50,5 & 51,8 & 52,2 & 37,2 & $50,8 A^{*}$ \\
\hline $\begin{array}{l}\text { Aveia+Azevém } \\
\text { Oat }+ \text { Ryegrass }\end{array}$ & 63,4 & 56,8 & 51,1 & 54,4 & 57,9 & 50,4 & $55,6 \mathrm{~A}$ \\
\hline $\begin{array}{l}\text { Triticale }+ \text { Aveia }+ \text { Azevém } \\
\text { Triticale }+ \text { Oat }+ \text { Ryegrass }\end{array}$ & 54,4 & 48,8 & 41,5 & 39,9 & 38,5 & 29,4 & 42,1B \\
\hline $\begin{array}{l}\text { Média } \\
\text { Mean }\end{array}$ & $59,2 a^{* *}$ & $53,1 \mathrm{ab}$ & $47,7 \mathrm{~b}$ & $48,7 \mathrm{~b}$ & $49,5 b$ & $39,0 \mathrm{c}$ & \\
\hline
\end{tabular}

* Médias na coluna, seguidas por letras diferentes (A, B) são diferentes $(P<0,05)$.

** Médias, na linha, seguidas por letras diferentes (a, b, c) são diferentes $(P<0,05)$.

* Means, within a column, followed by different letters $(A, B)$ are different $(P<.05)$

${ }^{* *}$ Means, within a row, followed by different letters $(a, b, c)$ are different $(P<.05)$.

Tabela 4 - Produção de matéria seca ( $\mathrm{kg}$ de MS/ha) da pastagem com misturas de gramíneas anuais de estação fria sob pastejo Table 4 - Dry matter production (kg of DM/ha) in annual temperate grasses mixtures under continuous grazing

\begin{tabular}{|c|c|c|c|c|c|c|c|}
\hline \multirow{4}{*}{$\begin{array}{l}\text { Tratamento } \\
\text { Treatment }\end{array}$} & \multicolumn{7}{|c|}{ Mês } \\
\hline & \multicolumn{7}{|c|}{ Month } \\
\hline & $21 / 04$ a $30 / 06$ & 01/07a $31 / 07$ & $01 / 08$ a $31 / 08$ & 01/09a 30/09 & $01 / 10$ a $31 / 10$ & $01 / 11$ a $14 / 11$ & Total \\
\hline & $04 / 21$ to $06 / 30$ & $07 / 01$ to $07 / 31$ & $08 / 01$ to $08 / 31$ & $09 / 01$ to $09 / 30$ & $10 / 01$ to $10 / 31$ & $11 / 01$ to $11 / 14$ & \\
\hline Triticale+Azevém & 2766 & 1668 & 1565 & 1554 & 1618 & 525 & $9696 \mathrm{~A}^{*}$ \\
\hline Triticale + Ryegrass & & & & & & & \\
\hline Aveia+Azevém & 2798 & 1761 & 1581 & 1632 & 1795 & 706 & $10273 \mathrm{~A}$ \\
\hline Oat + Ryegrass & & & & & & & \\
\hline $\begin{array}{l}\text { Triticale }+ \text { Aveia }+ \text { Azevém } \\
\text { Triticale }+ \text { Oat }+ \text { Ryegrass }\end{array}$ & 2440 & 1513 & 1286 & 1197 & 1193 & 412 & $8041 \mathrm{~B}$ \\
\hline
\end{tabular}

* Médias, na coluna, seguidas por letras diferentes $(A, B)$ são diferentes $(P<0,05)$.

${ }^{*}$ Means, within a column, followed by different letters $(A, B)$ are different $(P<.05)$.

preta mais azevém. A menor taxa de acumulação de matéria seca verificada no presente experimento, provavelmente, ocorreu em virtude do déficit hídrico (Tabela 1) e do maior período de utilização da pastagem, pois esses autores avaliaram as pastagens por um período mais curto, de agosto a início de novembro, em que as temperaturas e o fotoperíodo são mais favoráveis para o crescimento das plantas.

$\mathrm{Na}$ média dos tratamentos, a taxa de acumulação de matéria seca também foi influenciada pelo período, sendo que as pastagens nos meses de junho e julho apresentaram as maiores taxas de acumulação e valores menores para os meses de agosto a novembro. Resultados diferentes foram encontrados por LUPATINI et al. (1998), em que as maiores taxas de acumulação ocorreram nos meses de setembro e outubro, quando as temperaturas são mais favoráveis ao desenvolvimento do azevém.

A estabilidade na produção de matéria seca ao longo do período de pastejo é importante, pois facilita o manejo da pastagem, evitando assim grandes variações na carga animal necessária para a mantença de resíduo adequado, visando maximizar a produção, tanto animal como de forragem. A oscilação que freqüentemente ocorre na taxa de acumulação de matéria seca das pastagens, devido às variações climáticas e à estacionalidade de produção das espécies utilizadas, é a maior dificuldade enfrentada no manejo de pastagens com o sistema de pastejo contínuo, com lotação variável, pois ocorre variação na capacidade de suporte da pastagem, havendo grande variação no número de animais necessário para o ajuste da lotação. 
A produção total de MS (Tabela 4) da semeadura (21/04) até o final da utilização (14/11) foi superior nas misturas de triticale mais azevém e aveia preta mais azevém em relação à mistura das três espécies, produzindo, respectivamente, $9696,10.273$ e $8041 \mathrm{~kg}$ de $\mathrm{MS} / \mathrm{ha}$.

O percentual dos componentes botânicos dos resíduos das misturas são apresentados na Tabela 5, na qual se observa que houve maior participação inicial das espécies de triticale e aveia preta, contribuindo, respectivamente, com 83,8 e $89,5 \%$ das misturas com azevém. Já na mistura com as três espécies, a participação do triticale e aveia foi de 42,3 e $46,5 \%$, respectivamente. Estes resultados evidenciam a precocidade destas duas espécies e a sua contribuição na produção de forragem, quando da associação com o azevém, que apresenta pequena participação inicial.

A partir de julho, houve decréscimo na participação do triticale e da aveia preta no resíduo e aumento da contribuição do azevém, sendo que a maior diminuição ocorreu para a aveia preta, apesar de sua maior participação nos primeiros períodos, chegando no final de setembro com apenas $3,7 \%$ contra $12,2 \%$ do triticale, o que mostra a maior persistência do triticale na condição de pastejo, provavelmente por apresentar maior produção de afilhos vigorosos. Estas observações concordam com a afirmação de FLOSS (1989) de que a aveia preta apresenta rápido crescimento inicial, com diminuição da produção nos períodos posteriores. Acompanhando a queda na participação dos componentes triticale e aveia preta, houve grande participação de material morto no resíduo, sendo de 23,9;36,4; e 29,8\% na avaliação de $17 / 8$, respectivamente, para os tratamentos com triticale ou aveia preta ou triticale e aveia preta mais azevém, devido à senescência das plantas de triticale e aveia, que, ao se aproximarem da fase reprodutiva, emitiram inflorescências e foram pastejadas, eliminando, portanto, os pontos de crescimento.

Houve pequena contribuição do componente azevém na primeira avaliação do resíduo, com percentuais de 16,$2 ; 10,6$; e 11,2, chegando aos valores máximos em setembro, 67,$2 ; 77,7 ; 67,6$, e outubro, 68,$5 ; 69,5 ; 68,3 \%$, para T1, T2 e T3, respectivamente. Estes resultados têm respaldo na afirmação de FLOSS (1989), o qual relata que o azevém apresenta desen-

Tabela 5 - Componente botânico (\%) dos resíduos da pastagem com misturas de gramíneas anuais de estação fria sob pastejo contínuo, por tratamento, período de avaliação e médias

Table 5 - Botanical composition (\%) of the residuals of the pasture of annual temperate grasses mixtures under continuous grazing, per treatment, evaluation period and means

\begin{tabular}{|c|c|c|c|c|c|c|c|}
\hline \multirow[t]{2}{*}{$\begin{array}{l}\text { Componente } \\
\text { Component }\end{array}$} & \multicolumn{7}{|c|}{$\begin{array}{l}\text { Avaliação } \\
\text { Evaluation }\end{array}$} \\
\hline & $08 / 06$ & $13 / 07$ & $17 / 08$ & $20 / 09$ & $30 / 10$ & $14 / 11$ & Média (Mean) \\
\hline Triticale & 83,8 & 66,3 & 35,6 & 12,2 & - & - & 33,0 \\
\hline Azevém & 16,2 & 33,7 & 40,5 & 67,2 & 68,5 & 40,1 & 44,4 \\
\hline Ryegrass & & & & & & & \\
\hline $\begin{array}{l}\text { Material morto } \\
\text { Dead material }\end{array}$ & - & - & 23,9 & 19,3 & 27,6 & 59,9 & 21,8 \\
\hline $\begin{array}{l}\text { Inços } \\
\text { Weeds }\end{array}$ & - & - & - & 01,3 & 03,8 & - & 00,9 \\
\hline $\begin{array}{l}\text { Aveia preta } \\
\text { Oat }\end{array}$ & 89,5 & 77,8 & 16,0 & 03,7 & - & - & 31,2 \\
\hline $\begin{array}{l}\text { Azevém } \\
\text { Ryegrass }\end{array}$ & 10,6 & 22,2 & 44,6 & 77,7 & 69,5 & 45,5 & 45,0 \\
\hline $\begin{array}{l}\text { Material morto } \\
\text { Dead material }\end{array}$ & - & - & 36,4 & 16,2 & 25,1 & 54,5 & 22,0 \\
\hline $\begin{array}{l}\text { Inços } \\
\text { Weeds }\end{array}$ & - & - & 03,0 & 02,4 & 05,4 & - & 01,8 \\
\hline Triticale & 42,3 & 45,1 & 15,1 & 02,9 & - & - & 17,6 \\
\hline $\begin{array}{l}\text { Aveia preta } \\
\text { Oat }\end{array}$ & 46,5 & 33,1 & 13,5 & 05,5 & - & - & 16,4 \\
\hline $\begin{array}{l}\text { Azevém } \\
\text { Ryegrass }\end{array}$ & 11,2 & 17,1 & 40,3 & 67,6 & 68,3 & 39,6 & 40,7 \\
\hline $\begin{array}{l}\text { Material morto } \\
\text { Dead material }\end{array}$ & - & 04,7 & 29,8 & 23,4 & 30,0 & 60,4 & 24,7 \\
\hline $\begin{array}{l}\text { Inços } \\
\text { Weeds }\end{array}$ & - & - & 01,2 & 00,5 & 01,6 & - & 00,55 \\
\hline
\end{tabular}


volvimento lento em temperaturas baixas e aumenta a produção de matéria seca com as temperaturas mais elevadas da primavera. Constatou-se maior participação inicial do azevém na mistura com triticale, pois, devido ao fato de as plantas de triticale terem apresentado colmos com mais carboidratos estruturais em relação à aveia preta, estes propiciaram menor acamamento inicial, que foi observado na aveia, e também por apresentarem arquitetura folhar, que permite maior passagem de luminosidade para os estratos inferiores da pastagem, favorecendo o estabelecimento inicial do azevém.

Os valores da DIVMO dos componentes botânicos encontram-se na Tabela 6. Não houve diferenças entre as mesmas espécies que formaram as diferentes misturas, portanto, os valores são apresentados por espécie, independente de mistura. Verificaramse maior DIVMO nas avaliações iniciais (08/06 e 13/07), quando as espécies se encontravam em pleno estádio de crescimento vegetativo, e redução acentuada na terceira avaliação (17/08), principalmente para a aveia preta e o triticale, período que coincidiu com o final do ciclo de produção destas espécies. O azevém apresentou maior digestibilidade na avaliação inicial (08/06), com queda acentuada para a segunda (13/07) e terceira (17/08) avaliações, mantendo-se constante até o final do período de utilização da pastagem. A redução no valor nutritivo das espécies com o avanço nos períodos coincide com o avanço nos estádios de desenvolvimento das plantas, em que ocorre aumento dos tecidos de sustentação constituídos por carboidratos estruturais e lignina (BLASER, 1990).

Analisando a digestibilidade do material considerado morto, observa-se aumento nas avaliações finais $(31 / 10$ e $14 / 11)$, devido ao fato de grande parte do percentual do material morto ser constituído por plantas de azevém que haviam acabado de completar o ciclo produtivo e ainda apresentavam DIVMO relativamente boa.

$\mathrm{O}$ teor de PB das espécies usadas nas misturas estão na Tabela 7. Não houve diferenças entre as mesmas espécies que formavam as diferentes misturas, portanto, os valores são apresentados por espécie, independente de mistura. Os resultados demonstram o elevado teor de PB das espécies avaliadas, em que os maiores valores foram obtidos no início do pastejo (08/06), sendo de 28,$8 ; 28,6$; e $31,6 \%$ para o triticale, aveia e azevém, respectivamente, decrescendo com o passar dos períodos, chegando ao final da participação em 20/9 com 19,1 e 19,4\% para o triticale e a aveia e em $14 / 11$ com $12,2 \%$ para o azevém. Estes resultados mostram que as espécies estudadas apresentaram durante todo o período de utilização teor de proteína bruta satisfatório, para a obtenção de elevado desempenho animal. A queda no teor de PB, com o avanço nos estádios de desenvolvimento, ocorreu devido à perda de folhas, ocasionadas pelo pastejo seletivo, ao decréscimo natural na relação folha/caule e à acelerada taxa de acumulação de materiais estruturais.

Os valores de DIVMO do resíduo por avaliação e na média do período experimental estão na Tabela 8. Pode-se observar maior digestibilidade no início da utilização da pastagem, decrescendo com o avanço dos períodos, principalmente da primeira para a terceira avaliação, provavelmente em função da diminuição no percentual de folhas, e aumento no componente material morto, entre outros. Na quarta avaliação, houve aumento na DIVMO, devido à maior participação do azevém, e menor contribuição percentual do material morto, ocorrendo redução

Tabela 6 - Digestibilidade in vitro da matéria orgânica (\%) dos componentes botânicos por período de avaliação da pastagem com misturas de gramíneas anuais de estação fria sob pastejo contínuo

Table 6 - In vitro organic matter disappearance (\%) of the botanical components per evaluation period of the pasture of annual temperate grasses mixtures under continuous grazing

\begin{tabular}{lcccccc}
\hline $\begin{array}{l}\text { Componente } \\
\text { Component }\end{array}$ & \multicolumn{5}{c}{$\begin{array}{c}\text { Avaliação } \\
\text { Evaluation }\end{array}$} \\
\cline { 2 - 7 } & $08 / 06$ & $13 / 07$ & $17 / 08$ & $20 / 09$ & $30 / 10$ & $14 / 11$ \\
\hline Triticale & 69,9 & 70,8 & 53,3 & - & - & - \\
Aveia preta & 67,1 & 68,0 & 54,3 & - & - & - \\
$\begin{array}{l}\text { Oat } \\
\text { Azevém }\end{array}$ & 72,3 & 66,9 & 57,3 & 58,5 & 58,8 & 53,3 \\
$\begin{array}{l}\text { Ryegrass } \\
\text { Material morto }\end{array}$ & - & - & 34,4 & 30,7 & 39,1 & 42,3 \\
Dead material & & & & & \\
\hline
\end{tabular}


acentuada nas avaliações posteriores, em função do final do ciclo produtivo do azevém.

A DIVMO média do período experimental foi semelhante entre as misturas, sendo de 56,4; 56,7; e $57,5 \%$ para $\mathrm{T} 1, \mathrm{~T} 2$ e $\mathrm{T} 3$, respectivamente, pois não houve diferenças marcantes no percentual e na DIVMO dos componentes triticale e aveia preta nos resíduos das diferentes misturas. Estes resultados são semelhantes aos encontrados por CANTO et al. (1997), usando aveia preta mais $100 \mathrm{~kg}$ de N/ha, RESTLE et al. (1997), utilizando mistura de aveia preta + azevém, e LESAMA (1997), trabalhando com misturas de aveia preta mais azevém com trevo vesiculoso e ou adubadas com nitrogênio. Valores superiores foram encontrados por LUPATINI et al. (1998), trabalhando com níveis de nitrogênio em aveia preta mais azevém sob pastejo de meados de julho até finais de outubro, CANTO et al. (1997), quando utilizaram a mistura de aveia preta, azevém e ervilhaca, e QUADROS e MARASCHIN (1987), utilizando com leguminosas e gramíneas de estação fria sob pastejo.

No teor de proteína bruta do resíduo (Tabela 8) foi verificada interação significativa entre tratamento e período, sendo que no primeiro e sexto período não houve diferença significativa entre as misturas. Já no segundo, terceiro, quarto e quinto período ocorreu diferença significativa entre os tratamentos. No segundo período o maior valor foi observado na mistura de triticale + azevém; no terceiro e quinto, o maior teor de PB foi observado no T2 e o menor, no T3, sendo que o T1 apresentou comportamento intermediário; e no quarto, o menor teor de PB foi obtido no $\mathrm{T} 1$, diferindo dos demais tratamentos.
Os maiores teores de proteína bruta foram verificados no início da utilização da pastagem, devido ao grande percentual de folhas presente no resíduo, ocorrendo redução acentuada nas avaliações seguintes, causada por aumento na quantidade de colmos e diminuição da área folhar ocasionada pelo pastejo. A partir da terceira avaliação, houve pequeno incremento no teor de PB pela grande contribuição do componente azevém, que apresentou elevado teor de PB; posteriormente, ocorreu redução devido ao final do ciclo das plantas, chegando em 14/11 com 11,6\% de PB. Os resultados mostram que o teor de proteína bruta do resíduo, em todo o período de utilização da pastagem, não foi fator limitante para o desempenho animal.

A porcentagem de matéria seca (MS) por período de avaliação e na média encontra-se na Tabela 8 . Observa-se, na média das avaliações, que o menor teor de MS ocorreu na mistura de aveia preta com azevém. Analisando o teor de MS médio por avaliação, verifica-se o baixo conteúdo de MS presente nas avaliações inicias da pastagem (08/06 e 13/07), com percentuais de 12,4 e 13,4 de MS, respectivamente, ocorrendo aumento gradativo nas avaliações seguintes, chegando ao final de outubro com $27,5 \%$ e em 14/ 11 com 45,1\% de MS. O alto conteúdo de água presente nas pastagens de estação fria, principalmente nos pastejos iniciais, é um dos principais fatores limitantes no desempenho de animais em pastejo, pois o excesso de água presente nas células da forragem possui poder de enchimento, reduzindo a quantidade de matéria seca ingerida. Segundo COMERON (1997), a quantidade de MS ingerida pelos animais está ligada positiva e significativamente à porcentagem de MS da planta.

Tabela 7 - Teor de proteína bruta (\%) na matéria seca dos componentes botânicos, de acordo com o período de avaliação na pastagem com misturas de gramíneas anuais de estação fria sob pastejo contínuo

Table 7 - $\quad$ Crude protein content (\%) of the dry matter of the botanical components according to the evaluation period of the pasture of annual temperate grasses mixtures under continuous grazing

\begin{tabular}{|c|c|c|c|c|c|c|}
\hline \multirow[t]{2}{*}{$\begin{array}{l}\text { Componente } \\
\text { Component }\end{array}$} & \multicolumn{6}{|c|}{$\begin{array}{l}\text { Avaliação } \\
\text { Evaluation }\end{array}$} \\
\hline & $08 / 06$ & $13 / 07$ & $17 / 08$ & $20 / 09$ & $30 / 10$ & $14 / 11$ \\
\hline Triticale & 28,8 & 18,8 & 19,1 & - & - & - \\
\hline $\begin{array}{l}\text { Aveia preta } \\
\text { Oat }\end{array}$ & 28,6 & 22,1 & 19,4 & - & - & - \\
\hline $\begin{array}{l}\text { Azevém } \\
\text { Rvegrass }\end{array}$ & 31,6 & 19,9 & 23,9 & 21,7 & 15,3 & 12,2 \\
\hline $\begin{array}{l}\text { Material morto } \\
\text { Dead material }\end{array}$ & - & - & 11,1 & 14,2 & 14,0 & 11,2 \\
\hline
\end{tabular}


Tabela 8 - Digestibilidade in vitro da matéria orgânica (DIVMO), teor de proteína bruta (PB) e porcentagem de matéria seca (MS) dos resíduos de acordo com o período de avaliação e na média da pastagem com misturas de gramíneas anuais de estação fria sob pastejo contínuo

Table 8 - In vitro organic matter disappearance (IVOMD), crude protein content (CP) and dry matter percentage (DM) of the residuals according to the evaluation period and average of the pasture of annual temperate grasses mixtures under continuous grazing

Componente

Component Avaliação

\begin{tabular}{|c|c|c|c|c|c|c|c|}
\hline \multirow[t]{2}{*}{ Component } & \multicolumn{7}{|c|}{ Evaluation } \\
\hline & $08 / 06$ & $13 / 07$ & $17 / 08$ & $20 / 09$ & $30 / 10$ & $14 / 11$ & Média (Mean) \\
\hline & \multicolumn{7}{|c|}{ DIVMO (IVOMD), $\%$} \\
\hline \multirow{2}{*}{\multicolumn{8}{|c|}{$\begin{array}{l}\text { Triticale }+ \text { Azevem } \\
\text { Triticale }+ \text { Ryegrass }\end{array}$}} \\
\hline & & & & & & & \\
\hline Aveia+Azevém & 64,4 & 57,1 & 57,3 & 64,1 & 50,9 & 46,5 & 56,7 \\
\hline \multicolumn{8}{|l|}{ Oat + Ryegrass } \\
\hline Triticale + Aveia + Azevém & 65,5 & 60,8 & 61,0 & 58,2 & 55,1 & 44,6 & 57,5 \\
\hline \multicolumn{8}{|l|}{ Triticale + Oat + Ryegrass } \\
\hline \multirow[t]{2}{*}{ Média(Mean) } & $64,3 \mathrm{a} * *$ & $60,4 \mathrm{~b}$ & $58,9 \mathrm{~b}$ & $60,9 \mathrm{ab}$ & $50,6 \mathrm{c}$ & $46,1 \mathrm{~d}$ & \\
\hline & \multicolumn{7}{|c|}{$\mathrm{PB}(C P), \%$} \\
\hline Triticale+Azevém & 29,0 & $16,8 \mathrm{~A}^{*}$ & $16,1 \mathrm{AB}$ & $16,4 \mathrm{~B}$ & $12,7 \mathrm{AB}$ & 11,4 & 17,7 \\
\hline \multicolumn{8}{|l|}{ Triticale + Ryegrass } \\
\hline Aveia+Azevém & 30,6 & 14,1 B & $17,8 \mathrm{~A}$ & $20,0 \mathrm{~A}$ & $14,5 \mathrm{~A}$ & 11,7 & 18,1 \\
\hline \multicolumn{8}{|l|}{ Oat + Ryegrass } \\
\hline Triticale+Aveia+Azevém & 29,5 & $14,4 \mathrm{~B}$ & $14,2 \mathrm{~B}$ & $16,6 \mathrm{~A}$ & $10,6 \mathrm{~B}$ & 11,0 & 16,2 \\
\hline \multicolumn{8}{|l|}{ Triticale + Oat + Ryegrass } \\
\hline \multirow[t]{2}{*}{ Média (Mean) } & 29,7 & 15,1 & 16,1 & 17,7 & 12,6 & 11,6 & \\
\hline & \multicolumn{7}{|c|}{$\mathrm{MS}(D M), \%$} \\
\hline Triticale+Azevém & 15,2 & 14,5 & 15,6 & 20,3 & 27,5 & 44,9 & $23,0 A^{*}$ \\
\hline \multicolumn{8}{|l|}{ Triticale + Ryegrass } \\
\hline Aveia+Azevém & 10,9 & 12,5 & 15,6 & 18,3 & 27,0 & 43,2 & $21,2 \mathrm{~B}$ \\
\hline \multicolumn{8}{|l|}{ Oat + Ryegrass } \\
\hline Triticale+Aveia+Azevém & 11,2 & 13,2 & 16,9 & 22,3 & 28,2 & 47,3 & $23,2 \mathrm{~A}$ \\
\hline \multicolumn{8}{|l|}{ Triticale + Oat + Ryegrass } \\
\hline Média(Mean) & $12,4 \mathrm{e}^{* *}$ & $13,4 \mathrm{e}$ & $16,0 \mathrm{~d}$ & $20,3 \mathrm{c}$ & $27,5 b$ & $45,1 \mathrm{a}$ & \\
\hline
\end{tabular}

* Médias, na coluna seguidas por letras diferentes $(A, B)$ são diferentes $(P<0,05)$.

** Médias, na linha, seguidas por letras diferentes (a, b, c) são diferentes $(P<0,05)$.

* Means, within a column, followed by different letters $(A, B)$ are different $(P<.05)$

${ }^{* *}$ Means, within a row, followed by different letters $(a, b, c)$ are different $(P<.05)$.

\section{Conclusões}

A mistura triticale mais azevém apresenta melhor distribuição na produção e maior estabilidade na qualidade de forragem.

A mistura aveia preta mais azevém apresenta menor teor de MS ao longo do período de utilização.

O triticale e aveia preta apresentam maior contribuição nos pastejos no início do ciclo da mistura e o azevém no período final.

O triticale e a aveia preta apresentam elevado potencial de produção de forragem e, quando utilizados na mistura com o azevém, resultam em longo período de utilização, com alta produção de forragem de elevada qualidade.

A mistura de triticale mais aveia preta mais azevém produz menos MS/ha que as misturas de triticale mais azevém ou aveia mais azevém.

\section{Agradecimentos}

Ao Professor José Henrique Souza da Silva $(\mathrm{PhD})$, pela colaboração na execução da análise estatística deste trabalho.

\section{Referências Bibliográficas}

ASSOCIATION OF OFFICIAL ANALYTICAL CHEMISTS AOAC.1984. Official methods of analysis. $14 \mathrm{ed}$. Washington, $1141 \mathrm{p}$

BAIER, A.C. Triticale. In: BAIER, A.C., AUDE, M.I.S., FLOSS, E.L. 1989. As lavouras de inverno-1. São Paulo: Globo, p.76-106.

BAIER, A.C., NEDEL, J.L. 1985. Potencial do triticale no Brasil. Pesq. Agropec. Bras., 20(1):57-67.

BLASER, R.E. 1990. Manejo do complexo pastagem-animal para avaliação de plantas e desenvolvimento de sistemas de produção de forragens. In: PASTAGENS. Piracicaba: FEALQ. 205p. p. 157-205.

CANTO, M.W., RESTLE, J., QUADROS, F.L.F. et al. 1997. 
Rev. bras. zootec.

Produção animal em pastagem de aveia (Avena strigosa Schreb) adubada com nitrogênio ou em mistura com ervilhaca (Vicia sativa L.). R. Soc. Bras. Zootec., 26(2):396-402.

COMERON, E.A. Efectos de la calidad de los forrajes y la suplementacion en el desempeño de ruminantes en pastoreo (con especial referencia a vacas lecheras) In: SIMPÓSIO SOBRE AVALIAÇÃO DE PASTAGENS COM ANIMAIS, 1997, Maringá, PR. Anais... Maringá: UEM, 1997. 149 p. p. 53-73.

FLOSS, E.L. 1989. Aveia. In: BAIER, A.C., AUDE, M.I.S., FLOSS, E.L. As lavouras de inverno-1. São Paulo: Globo. p.76-106.

LESAMA, M.F. Produção animal em gramíneas de estação fria com fertilização nitrogenada ou associadas com leguminosa, com ou sem fertilização nitrogenada. Santa Maria: UFSM, 1997. 129p. Dissertação (Mestrado em Zootecnia) - Universidade Federal de Santa Maria, 1997.

LUPATINI, G.C., RESTLE, J., CERETTA, M. et al.1998. Avaliação da mistura de aveia preta (Avena strigosa) e azevém (Lolium multiflorum) sob pastejo submetida a níveis de nitrogênio. I Produção e qualidade de forragem. Pesq. Agropec. Bras., 23(11):1939-1943.

MOREnO, J.A. 1961. Clima do Rio Grande do Sul. Porto Alegre: Secretaria da Agricultura. 41p.

QUADROS, F.L.F., MARASCHIN, G.E. 1987. Desempenho animal em misturas de espécies forrageiras de estação fria. Pesq. Agropec. Bras., 22(5):535-541.

RECOMENDAÇÕES DE ADUBAÇÃO E CALAGEM PARA OS ESTADOS DO RIO GRANDE DO SUL E SANTA CATARINA. 1989. 2. ed Passo Fundo: SBCS, Núcleo Regional Sul - EMBRAPA - CNPT. 128p.
RESTLE, J., LUPATINI, G.C., ROSO, C. et al. 1998. Eficiência e desempenho de diferentes categorias de bovinos de corte em pastagem cultivada. R. Bras. Zootec., 27(2):397-404.

RESTLE, J., ROSO, C., SOARES, A.B. Dinâmica de uma pastagem de aveia preta (Avena strigosa) e azevém (Lolium multiflorum) submetida a fontes de nitrogênio. In: REUNIÃO ANUAL DA SOCIEDADE BRASILEIRA DE ZOOTECNIA, 34, 1997, Juiz de Fora. Anais... Viçosa: SBZ. 1997. p.179-181. SAS, Institute Inc. 1990. SAS Language reference. Version 6, Cary, NC: SAS Institute Inc. 1042p.

TILLEY, J.M.A., TERRY, R.A. 1963. A two- stage technique for the in vitro digestion of forage crop. J. Brit. Grass. Soc., 18(2):104-111.

Recebido em: 23/09/97

Aceito em: 02/12/98 